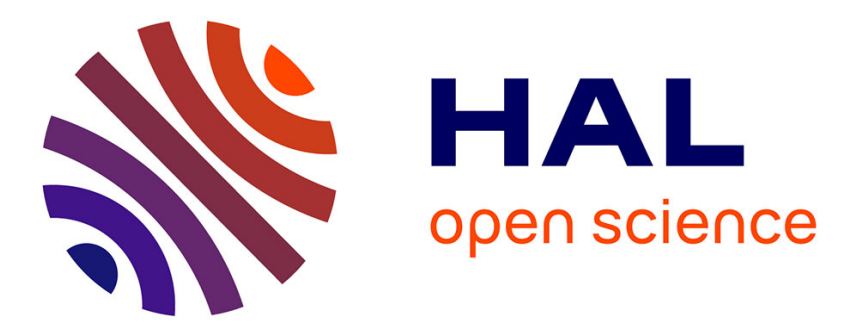

\title{
Effects of metal dilution on the spin-crossover behavior and light induced bistability of iron(II) in [FexNi1-x(bpp)2](NCSe)2
}

Chérif Baldé, Cédric Desplanches, Jean-François Létard, Guillaume Chastanet

\section{- To cite this version:}

Chérif Baldé, Cédric Desplanches, Jean-François Létard, Guillaume Chastanet. Effects of metal dilution on the spin-crossover behavior and light induced bistability of iron(II) in [FexNi1x(bpp)2](NCSe)2. Polyhedron, 2017, 123, pp.138-144. 10.1016/j.poly.2016.08.046 . hal-01444510

\author{
HAL Id: hal-01444510 \\ https://hal.science/hal-01444510
}

Submitted on 2 Mar 2021

HAL is a multi-disciplinary open access archive for the deposit and dissemination of scientific research documents, whether they are published or not. The documents may come from teaching and research institutions in France or abroad, or from public or private research centers.
L'archive ouverte pluridisciplinaire HAL, est destinée au dépôt et à la diffusion de documents scientifiques de niveau recherche, publiés ou non, émanant des établissements d'enseignement et de recherche français ou étrangers, des laboratoires publics ou privés. 


\title{
Effects of Metal Dilution on the Spin-Crossover Behavior and Light Induced Bistability of Iron(II) in $\left[\mathrm{Fe}_{x} \mathrm{Ni}_{1-x}(\mathrm{bpp})_{2}\right](\mathrm{NCSe})_{2}$
}

\author{
Chérif Baldé ${ }^{1,2,3 *}$, Cédric Desplanches ${ }^{2,3}$, Jean François Létard ${ }^{2,3}$, and Guillaume \\ Chastanet $^{2,3 *}$ \\ ${ }^{1}$ Laboratoire de Chimie et Physique des Matériaux (LCPM) Université Assane Seck de Ziguinchor, Sénégal \\ ${ }^{2}$ CNRS, ICMCB, UPR 9048, F-33600 Pessac, France \\ ${ }^{3}$ Univ. Bordeaux, ICMCB, UPR 9048, F-33600 Pessac, France \\ * Correspondence: guillame.chastanet@icmcb.cnrs.fr; cbalde@univ-zig.sn \\ Academic Editor: name \\ Received: date; Accepted: date; Published: date
}

\begin{abstract}
In this paper, we discuss the effects of metal dilution on the spin-crossover behavior of iron(II) solid solutions $\left[\mathrm{Fe}_{\mathrm{x}} \mathrm{Ni}_{1-\mathrm{x}}(\mathrm{bpp})_{2}\right](\mathrm{NCSe})_{2}$ (bpp $=2,6$-bis(pyrazol-3yl)pyridine), including chemical synthesis, physical properties and light induced bistability aspects. For all the materials investigated, the thermal spin-crossover properties, $T_{1 / 2}$, were measured and the stability of the photoinduced high-spin states was probed through determination of the T(LIESST) values associated with the light-induced excited spin-state trapping (LIESST) effect. It was found that $\mathrm{T}_{1 / 2}$ decreases with the metal dilution while T(LIESST) remains globally unchanged. These results were discussed and compared with previous results obtained in the same series with $\mathrm{Zn}$ (II) and $\mathrm{Mn}$ (II) used to substitute $\mathrm{Fe}(\mathrm{II})$. This comparison gives insights on the effect of the diluting ion size on the [T(LIESST), $\mathrm{T}_{1 / 2}$ ] temperatures.
\end{abstract}

Keywords: Spin Crossover (SCO); Dilution effects; Metal-coordination chemistry; LIESST; Iron

\section{Introduction}

Some molecular compounds, mostly those with an $\mathrm{Fe}^{\mathrm{II}} \mathrm{N}_{6}$ coordination environment, present a thermal Spin-CrossOver (SCO) transition between a high-spin (HS) state of electronic configuration $\mathrm{t}_{2 \mathrm{~g}}{ }^{4} \mathrm{e}_{\mathrm{g}}{ }^{2}\left({ }^{5} \mathrm{~T}_{2 \mathrm{~g}}, \mathrm{~S}=2\right)$ - and a low-spin (LS) state in the configuration $\mathrm{t}_{2 \mathrm{~g}}{ }^{6} \mathrm{eg}_{\mathrm{g}}{ }^{0}$ $\left({ }^{1} \mathrm{~A}_{1 \mathrm{~g}}, \mathrm{~S}=0\right)$. This transition is governed by the ligand-field strength and the intermolecular interactions in the crystal packing [1]. In fact, the competition between the electron pairing energy, the energy splitting between the $t_{2 g}$ and $e_{g}$ orbitals, the structural reorganization, and the entropy effects are balancing the stability of the LS and HS states at thermal equilibrium $[2,3]$. Along the SCO, strong structural rearrangements occur [4,5] due to the difference in volume between the compounds in the big HS state and the small LS state. This volume change, which could be anisotropic, propagates to the solid network through intermolecular interactions that determine the cooperative character of the SCO. Highly cooperative materials are usually characterized by hysteretic behaviors leading to memory effect. The bistability of SCO materials can be addressed with the application of various external stimuli like temperature, pressure, magnetic field or light irradiation [6]. The subsequent changes of physical properties (such as optical, magnetic, electrical properties...) along the LS $\leftrightarrow$ HS spin-state switching phenomenon are envisioned in applications such as in information storage, nano-devices and sensors [7-14]. The optical switching is particularly regarded since ultrafast switches (femtoseconds) can be achieved [15]. Light can reversibly write and erase 
the LS and HS states according to the direct or reverse light-induced excited spin state trapping (LIESST) effects [16-18]. Many investigations have been conducted since the discovery of the LIESST effect to understand and identify the parameters governing the lifetime of the photo-induced states. The role of intermolecular interactions on both thermal and light-induced spin-crossover has been investigated through the influence of the metal dilution in mixed [ $\left.\mathrm{Fe}_{\mathrm{x}} \mathrm{M}_{1-\mathrm{x}}\right]$ complexes with various metal ions [19-37]. Diluting the material with non-spin crossover metal sites disrupts the lattice cooperativity, resulting in a more gradual spin transition behavior. Moreover, the size of the dopant ion has a huge effect on the SCO properties. Indeed, ions with ionic radii close to or bigger than the ionic radius of the HS $\mathrm{Fe}$ (II) induce a negative internal pressure that favors the state of bigger volume, that is, the HS state. Diluting with $\mathrm{Zn}(\mathrm{II}), \mathrm{Mn}(\mathrm{II})$ or $\mathrm{Cd}(\mathrm{II})$ thus provokes a shift of the thermal spincrossover temperature at equilibrium, $\mathrm{T}_{1 / 2}$, toward low temperatures. The bigger the ion, the stronger the shift. Diluting with $\mathrm{Ni}$ (II) ion, which has an intermediate ionic radius between those of the LS and HS Fe(II) states, has no significant effect on the SCO properties [19]. The effect of metal dilution on light-induced spin-state lifetime was first reported by A. Hauser [38-40]. It was first shown that metal dilution changes the HS $\rightarrow$ LS relaxation behavior from a self-accelerated process - due to cooperativity - to an exponential process for isolated iron(II) ions. Hauser et al. [38,39,41] then showed that the thermally activated relaxation process is almost cooperativity independent. Later on, our group has studied extensively the effect of metal dilution on the LIESST temperature. This T(LIESST) temperature records the limit above which the photo-induced HS state cannot be observed with classical techniques (typically the ones that have a detection timescale on the order of a minute). At the end of numerous studies, we evidenced that the thermal spin crossover regime is mainly governed by the thermodynamics and cooperative interactions while the photo-induced HS state lifetime is mainly controlled at the molecular scale by the local environment [42,43]. In other words, while changes in counter-anions, solvent, ligands substituent... strongly affect the T(LIESST) value, the metal dilution that reduces the cooperativity does not modify it in a huge way [2633].

Up to now, the effect of metal dilution on T(LIESST) has been checked with $\mathrm{Zn}$ (II) or Mn(II), that are ions with volumes close to that of $\mathrm{Fe}$ (II) in the HS state. This has led to structures with an overlap between $\mathrm{T}(\mathrm{LIESST})$ and $\mathrm{T}_{1 / 2}$ [26,31-33]. In the present work we studied the "neutral" $\mathrm{Ni}$ (II) ion regarding the internal pressure it exerts on the Fe(II) network since it has an intermediate ionic radius $(\mathrm{r}=69 \mathrm{pm})$ with regard to the iron (II) metal radius of the HS (78 $\mathrm{pm})$ or the LS (61 pm) states [44]. The iron(II) SCO complex [Fe(bpp) $)_{2}$ (NCSe) $)_{2}$ has been selected in view of both its abrupt thermal spin transition, well defined with a small hysteresis loop of $2 \mathrm{~K}\left(\mathrm{~T}_{1 / 2} \downarrow=230 \mathrm{~K}, \mathrm{~T}_{1 / 2} \uparrow=232 \mathrm{~K}\right)$ [45], and its relatively high $\mathrm{T}(\mathrm{LIESST})$ value of about $75 \mathrm{~K}$ [42b]. For each $\left[\mathrm{Fe}_{\mathrm{x}} \mathrm{Ni}_{1-\mathrm{x}}(\mathrm{bpp})_{2}\right](\mathrm{NCSe})_{2}$ solid solution $(0.14 \leq \mathrm{x} \leq 1)$, we have measured systematically the $T_{1 / 2}$ and $T($ LIESST) values and investigated in details the relaxation process for each compound. We have previously reported studies on $\mathrm{Mn}$ (II) and $\mathrm{Zn}$ (II) solid solutions and we have demonstrated that the relaxation of the photo-induced metastable HS state of the iron(II) is weakly influenced by metal dilution. Indeed, the T(LIESST) was shown to be constant $[28,30]$ or slightly increased $[26,29,31,32,33]$ upon 
metal dilution. Two questions have motivated the present study: (i) Does the dilution with nickel induce an internal positive or negative pressure? (ii) Does nickel cause a decrease of T(LIESST)? We have then compared these previous results with the ones obtained with the $\mathrm{Ni}(\mathrm{II})$ ions, which is the smallest ion we can use for metal dilution, to understand how the amount and nature of M(II) molecular entities modify almost all of the spin transition properties. This paper addresses this issue through interpretation of the results obtained in this study in comparison with previous ones.

\section{Experimental section}

\subsection{Chemicals}

The preparation of [Fe(bpp) $\left.)_{2}\right](\mathrm{NCSe})_{2}, \mathbf{1}$, with bpp $=2,6$-bis(pyrazol-3-yl) pyridine has been described earlier by Sugiyarto et al. [45]. The diluted compounds $\left[\mathrm{Fe}_{\mathrm{x}} \mathrm{Ni}_{1-\mathrm{x}}\right]$ were synthesized according to the same procedure, replacing the metal salt by mixtures of iron(II) chloride and nickel(II) chloride in given ratios. The values of the iron fractions $(x)$ were calculated from the iron and nickel atomic percentages determined by quantitative analysis (ICP and CHN). The found and calculated values are in good agreement, as can be seen in Fig. 1 (a). The elemental analysis of $\mathrm{C}, \mathrm{H}, \mathrm{N}$ were performed on a FlashEA ${ }^{\mathrm{TM}} 1112$ elemental analyzer, and the results agreed well with the calculated data. 6 compounds were obtained with $x=1(\mathbf{1})$, $x=0.8$ (2), $x=0.6$ (3), $x=0.4$ (4), $x=0.14$ (5), $x=0$ (6). Elemental Anal. (\%) Calc. for compound 1 [Fe(bpp $)_{2}$ ](NCSe $)_{2}$ C 41.88, H 2.63, N 24.42; found C 41.55, H 2.62, N 24.46. Calc. for compound $2\left[\mathrm{Fe}_{0.8} \mathrm{Ni}_{0.2}(\mathrm{bpp})_{2}\right](\mathrm{NCSe})_{2} \mathrm{C} 41.84, \mathrm{H} 2.63, \mathrm{~N} 24.40$; found $\mathrm{C} 41.63, \mathrm{H}$ 2.61, N 24.45; Calc. for compound 3 [ $\left.\mathrm{Fe}_{0.6} \mathrm{Ni}_{0.4}(\mathrm{bpp})_{2}\right](\mathrm{NCSe})_{2} \mathrm{C} 41.81, \mathrm{H} \mathrm{2.63,} \mathrm{N} \mathrm{24.38;}$ found $\mathrm{C} 41.80, \mathrm{H} 2.61, \mathrm{~N} 24.52$; Calc. for compound 4 [Fe $\left.{ }_{0.4 \mathrm{Ni}} \mathrm{Ni}_{6}(\mathrm{bpp})_{2}\right](\mathrm{NCSe})_{2} \mathrm{C} 41.78, \mathrm{H}$ 2.63, N 24.36; found $\mathrm{C}$ 41.62, $\mathrm{H}$ 2.61, N 24.52. Calc. for compound $\mathbf{5}$ $\left[\mathrm{Fe}_{0.14} \mathrm{Ni}_{0.86}(\mathrm{bpp})_{2}\right](\mathrm{NCSe})_{2} \mathrm{C} 41.73, \mathrm{H} 2.62, \mathrm{~N} 24.33$; found $\mathrm{C} 41.48, \mathrm{H} 2.60, \mathrm{~N}$ 24.50. Calc. for compound $6\left[\mathrm{Ni}(\mathrm{bpp})_{2}\right](\mathrm{NCSe})_{2} \mathrm{C} 41.71, \mathrm{H} 2.62, \mathrm{~N} \mathrm{24.32}$; found $\mathrm{C} 41.69, \mathrm{H} \mathrm{2.61,} \mathrm{N}$ 24.53 .

\subsection{X-Ray powder diffraction.}

The X-ray powder diffraction of 1-6 have been recorded on a Philips PW1820 diffractometer provided by PANalytical X'Pert, using a Bragg-Bentano geometry $(\lambda=1.5406 \AA)$ from 5 to $50^{\circ}$ at $0.02^{\circ}$ s. Above $30^{\circ}$ the peak intensity was too weak to be relevant compared to the background.

\subsection{Magnetic and Photomagnetic Studies.}

Magnetic susceptibility data were collected using a Quantum Design MPMS 5 SQUID magnetometer under an applied field of $1 \mathrm{~T}$. All measurements were performed on homogenous polycrystalline samples and in the temperature range 10 to $290 \mathrm{~K}$. Diamagnetic corrections for the sample holder and the material (using Pascal constants) were applied.

Photomagnetic measurements were performed using a $\mathrm{Kr}+$ laser coupled via an optical fiber to the cavity of a MPMS-55 Quantum Design SQUID magnetometer operating at $2 \mathrm{~T}$. It was 
noted that there was no change in the data due to heating of the sample. The suspended crystalline sample was prepared in a thin layer $(\sim 0.1 \mathrm{mg})$ to promote full penetration of the irradiated light. The sample mass was obtained by comparison with the thermal spin transition curve measured on a larger accurately weighed polycrystalline sample. The calculated mass is of course approximate, however the adequacy between the bulk and thin layer magnetic measurements is reasonable, taking into account the fact that the data correction of such low amount of sample is challenging. Our previously published standardised method for obtaining LIESST data was followed [46]. The sample was first slow cooled to $10 \mathrm{~K}$, ensuring that potential trapping of HS species at low temperatures did not occur. Irradiation was carried out at a set of wavelength and the power on the sample surface was adjusted to $5 \mathrm{~mW} \mathrm{~cm}^{-2}$. Once photo-saturation was reached, irradiation was ceased and the temperature increased at a rate of $0.3 \mathrm{~K} \mathrm{~min}^{-1}$ to $\sim 100 \mathrm{~K}$ and the magnetisation measured every $1 \mathrm{~K}$ to determine the $T$ (LIESST) value $[42,46]$; given by the minimum of the $\partial \chi_{M} T / \partial T$ versus $T$ curve for the relaxation. The $T$ (LIESST) value describes the limiting temperature above which the lightinduced magnetic high-spin information is erased in a SQUID cavity. In the absence of irradiation, the magnetism was also measured over the temperature range $10-290 \mathrm{~K}$ to follow the thermal spin transition and to obtain a low temperature baseline. In addition to $T$ (LIESST) measurements, kinetic studies were performed by irradiating the sample at $10 \mathrm{~K}$ until photo-saturation, then, under constant irradiation the sample was warmed to a desired temperature around the T(LIESST) region. At the desired temperature, irradiation was ceased and the decay of the magnetization signal was followed for several hours, or until complete relaxation back to the low-spin baseline.

\subsection{Optical reflectivity measurements}

Variable temperature reflectivity measurements were performed using a home-built instrument coupled with a CVI spectrometer. This equipment can collect the reflectivity spectra in the $450-950 \mathrm{~nm}$ range at a given temperature, and also follow the temperature dependence of the signal at a selected wavelength $( \pm 2.5 \mathrm{~nm})$ between $10 \mathrm{~K}$ and $290 \mathrm{~K}$. The instrument is also equipped with an optical detector, which collected the whole reflected intensity and gave the total reflectivity signal as a function of temperature. The source of white light consisted of a halogen lamp emitting between 300 and $2400 \mathrm{~nm}$. This analysis was performed directly on a thin layer of the solid samples in the form of a polycrystalline powder without any dispersion in a matrix. It was checked that no change in the powder was recorded after a thermal cycle.

\section{Results and discussion}

Starting from the neat compound $\left[\mathrm{Fe}(\mathrm{bpp})_{2}\right](\mathrm{NCSe})_{2}$, 1, with bpp $=2$,6-bis (pyrazol-3-yl) pyridine, several solid solutions $\left[\mathrm{Fe}_{\mathrm{x}} \mathrm{Ni}_{1-\mathrm{x}}(\mathrm{bpp})_{2}\right](\mathrm{NCSe})_{2}$ were synthesized with $x=0.8(\mathbf{2})$, $x=0.6(3), x=0.4(\mathbf{4}), x=0.14(\mathbf{5})$, as well as the neat material $\left[\mathrm{Ni}(\mathrm{bpp})_{2}\right](\mathrm{NCSe})_{2}, \mathbf{6}$. No single crystals of the solid solutions could have been obtained. The composition was determined by elemental analysis, showing that the found and expected values (the ones calculated for the synthesis) are in good agreement, as can be seen in Fig. 1 (a). The powder 
X-Ray diffraction of the six compounds was recorded and the diffraction patterns reported on Figure $1 \mathrm{~b}$ show that all the compounds are isostructural.

(a)

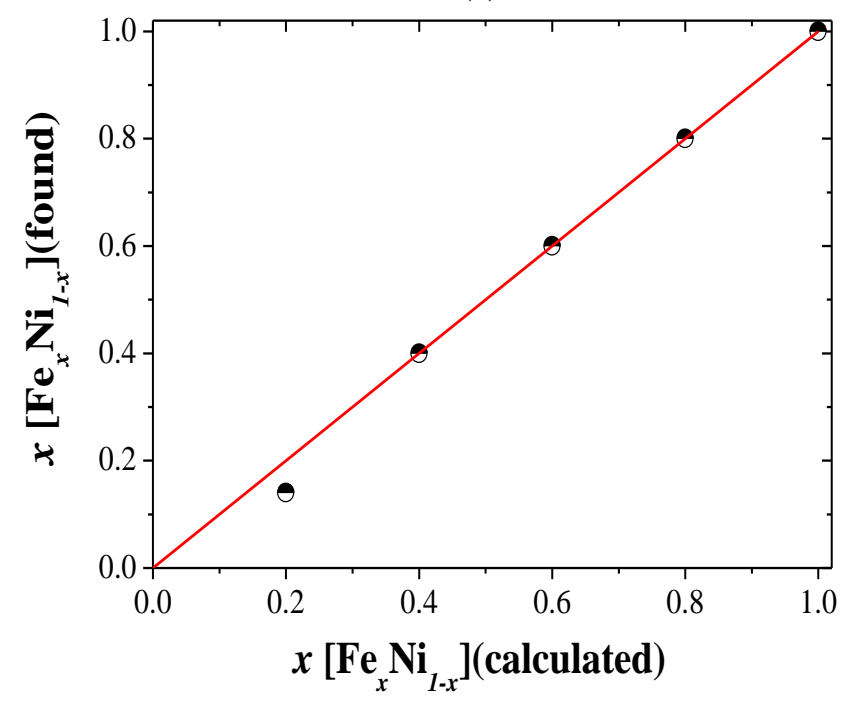

(b)

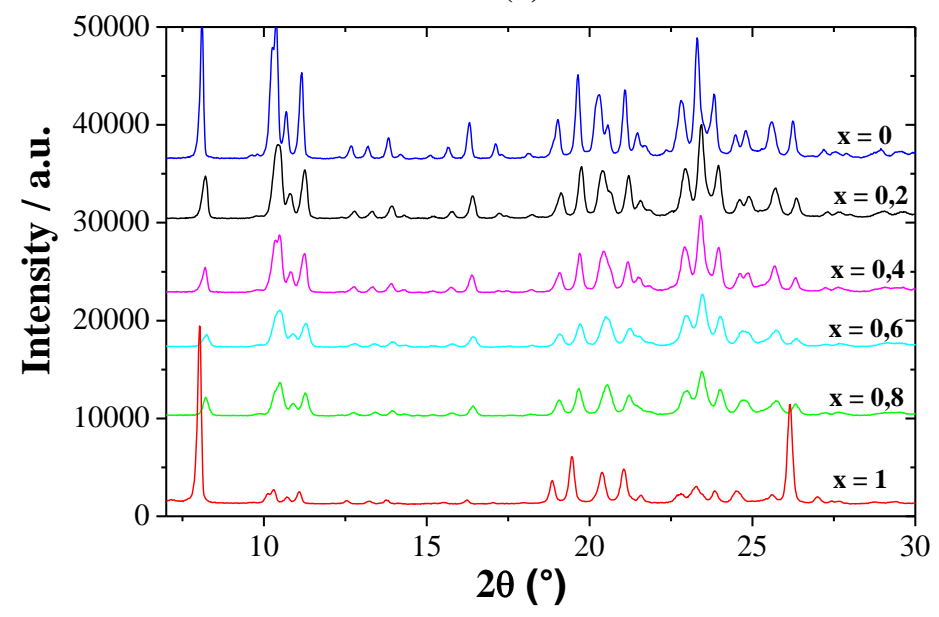

Fig 1. (a) Iron fraction $x$ obtained from elemental analysis $v s$. iron fraction calculated from the iron/nickel ratio used for the synthesis. The full line corresponds to the ideal situation where $x$ (found) $=x$ (calculated). (b) Roomtemperature X-ray powder diffraction patterns of $\left[\mathrm{Fe}_{\mathrm{x}} \mathrm{Ni}_{1-\mathrm{x}}(\mathrm{bpp})_{2}\right](\mathrm{NCSe})_{2}$

\subsection{Magnetic characterization}

The magnetic measurements were performed on polycrystalline samples and the thermal evolution of the molar magnetic susceptibility, $\chi_{M}$, times the temperature was followed. This measured $\chi_{M} \mathrm{~T}$ product is, in fact, the sum of the contributions of iron(II) ions and nickel(II) ions (equation (1)). To have access to the behavior of the iron ions, the magnetic contribution of the nickel ion has been removed according to equation (2). For that, the $\left(\chi_{M} T\right)_{\mathrm{Ni}}$ was experimentally measured on the pure $\left[\mathrm{Ni}(\mathrm{bpp})_{2}\right](\mathrm{NCSe})_{2}$ sample as: $\left(\chi_{\mathrm{M}} \mathrm{T}\right)_{\mathrm{Ni}} \approx 1.02 \mathrm{~cm}^{3} \cdot \mathrm{mol}^{-}$ ${ }^{1} . \mathrm{K}$, corresponding to the paramagnetic contribution of the nickel(II) ion $\left(\mathrm{d}^{8}, \mathrm{~S}=1\right)$. Figure 2 (a) reports the thermal dependence of the experimental $\chi_{M} \mathrm{~T}$ product relative to 1 mole of 
compounds 1-5. Since the iron(II) ions in the LS state are diamagnetic the $\left(\chi_{M} T\right)_{\mathrm{Fe}}$ product is proportional to the HS fraction $\left(\gamma_{\mathrm{HS}}\right)$. Thus, $\gamma_{\mathrm{HS}}$ may be directly deduced from the $\left(\chi_{\mathrm{MT}}\right)_{\mathrm{Fe}}$ product through equation (3) where $\left(\chi_{\mathrm{M}} \mathrm{T}\right)_{\mathrm{Fe}}{ }^{\mathrm{HT}}$ refers to the $\left(\chi_{\mathrm{M}} \mathrm{T}\right)_{\mathrm{Fe}}$ value at high temperatures, typically at $300 \mathrm{~K}$. Fig. 2 (b), shows the evolution of $\gamma_{\mathrm{HS}}$ as function of temperature in the cooling and heating modes, for all the mixed compounds under investigation.

$$
\begin{aligned}
& \chi_{M} T=x\left(\chi_{M} T\right)_{F e}+(1-x)\left(\chi_{M} T\right)_{N i} \\
& \left(\chi_{M} T\right)_{F e}=\frac{\chi_{M} T-(1-x)\left(\chi_{M} T\right)_{N i}}{x} \\
& \gamma_{H S}=\frac{\left(\chi_{M} T\right)_{F e}}{\left(\chi_{M} T\right)_{F e}}
\end{aligned}
$$

(a)

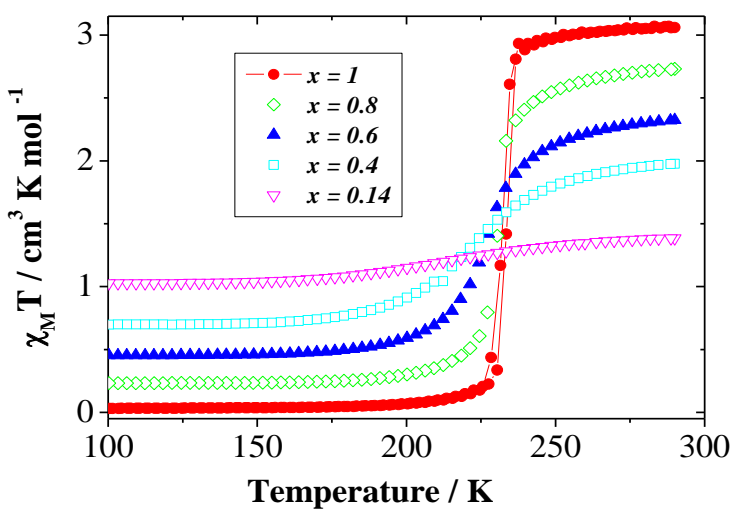

(b)

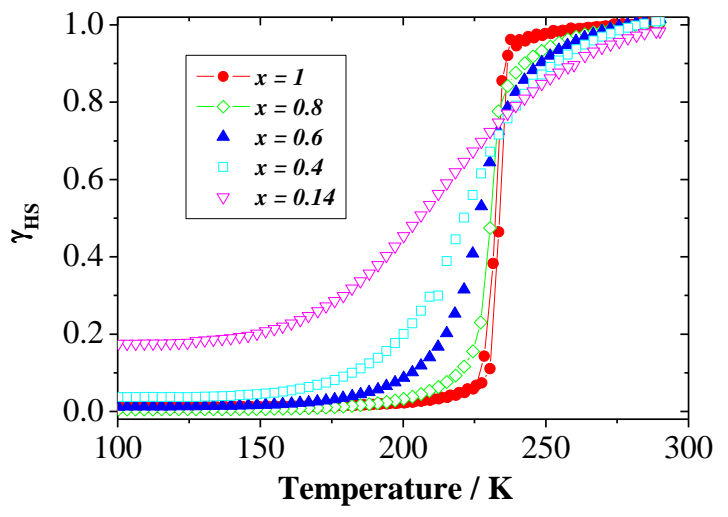

Fig 2. (a) Evolution of the $\chi_{M} \mathrm{~T}$ signal as function of $x$ curves for $\left[\mathrm{Fe}_{\mathrm{x}} \mathrm{Ni}_{1-\mathrm{x}}(\mathrm{bpp})_{2}\right](\mathrm{NCSe})_{2}$. (b) Evolution as a function of $\mathrm{x}$ of the $\gamma_{\mathrm{HS}} v s . \mathrm{T}$ curves obtained from magnetic susceptibility measurements for different iron concentration $\mathrm{x}$.

The thermal spin-crossover temperature, $T_{1 / 2}$, was estimated as the temperature at which $\gamma_{\mathrm{HS}}$ has the particular value $\gamma_{\mathrm{HS}}=\left(1-\mathrm{r}_{\mathrm{HS}}\right) / 2$, with $\mathrm{r}_{\mathrm{HS}}$ the residual paramagnetic quantity at low temperature (i.e. $50 \mathrm{~K}$ ). The information given by this data (Figure 3 ) agrees with the previous observations in metal dilution studies [19-37], i.e. when the metal dilution increases, we can notice that, (i) the transition temperature $\mathrm{T}_{1 / 2}$ shifts to lower temperatures which can be understood through a change of internal pressure; (ii) spin crossovers become globally more gradual and the hysteresis loop cancels out reflecting a progressive loss of cooperativity; (iii) a residual paramagnetism ( $\mathrm{r}_{\mathrm{HS}}$ ) appears for highly diluted system which is also a consequence of the negative pressure exerts by the nickel ions.

A comparison with the behavior reported for the zinc and manganese solid solutions stresses that the effect of nickel, on the thermal spin crossover, is less pronounced that the effect obtained by $\mathrm{Zn}$ (II) and $\mathrm{Mn}$ (II) in the same series [26,30]. If one considers the ionic radius of the different metal ions, $r\left(\mathrm{Mn}^{2+}, 83 \mathrm{pm}\right) ; r\left(F e_{H S}^{2+}, 78 \mathrm{pm}\right) ; r\left(\mathrm{Zn}^{2+}, 74 \mathrm{pm}\right)$; $r\left(N i_{H S}^{2+}, 69 \mathrm{pm}\right)$ and $r\left(\mathrm{Fe}_{L S}^{2+}, 61 \mathrm{pm}\right)$, this observation confirms that the larger the ion the better the HS state stability, inducing a more efficient shift of the thermal transition 
temperature toward low temperature. For example, for a metal dilution of about $x=0.2$, the $\mathrm{Mn}(\mathrm{II})$ host shifts the transition temperature, $\mathrm{T}_{1 / 2}$, to lower temperatures of about $130 \mathrm{~K}$ while the $\mathrm{Zn}$ (II) shifts $\mathrm{T}_{1 / 2}$ of about $82 \mathrm{~K}$ and $\mathrm{Ni}$ (II) which is the smallest of them moves $\mathrm{T}_{1 / 2}$ only about $17 \mathrm{~K}$ as shown in Fig. 3. This very small effect observed for the Ni(II) ion agrees with the previous studies [19] since the $\mathrm{Ni}(\mathrm{II})$ ion has an ionic radius $\mathrm{r}\left(\mathrm{Ni}^{2+}\right) \approx\left[\mathrm{r}\left(\mathrm{Fe}_{\mathrm{HS}}{ }^{2+}\right)+\right.$ $\left.\mathrm{r}\left(\mathrm{Fe}_{\mathrm{LS}}{ }^{2+}\right)\right] / 2$ resulting in an almost neutral internal pressure effect.

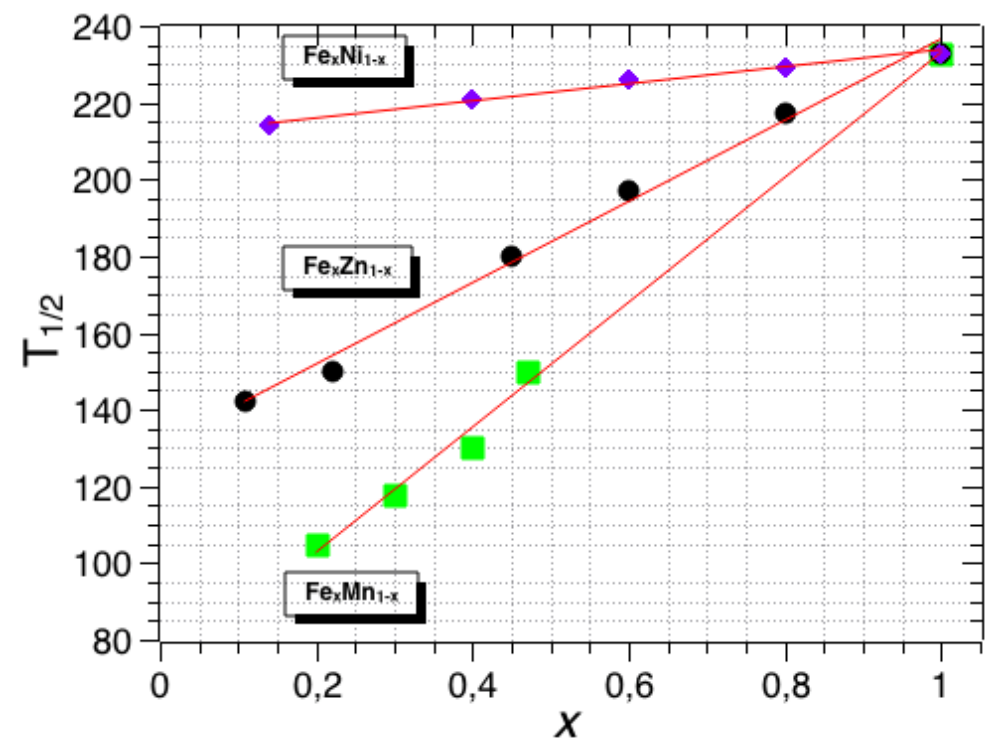

Fig 3. Concentration dependence of the transition temperature $\mathrm{T}_{1 / 2}$ for $\left[\mathrm{Fe}_{\mathrm{x}} \mathrm{Ni}_{1-\mathrm{x}}(\mathrm{bpp})_{2}\right](\mathrm{NCSe})_{2},\left[\mathrm{Fe}_{\mathrm{x}} \mathrm{Zn}_{1-}\right.$ $\left.{ }_{x}(\mathrm{bpp})_{2}\right](\mathrm{NCSe})_{2}$ and $\left[\mathrm{Fe}_{\mathrm{x}} \mathrm{Mn}_{1-\mathrm{x}}(\mathrm{bpp})_{2}\right](\mathrm{NCSe})_{2}$.

\subsection{Optical characterization}

Thermal spin-crossover can be monitored by following the visible spectrum of the powder sample. Changes in the diffuse absorption spectra measured as a function of temperature and light irradiation were used to follow the relative amounts of HS and LS iron(II) species. Typical spectra, recorded for $\left[\mathrm{Fe}_{0.4} \mathrm{Ni}_{0.6}(\mathrm{bpp})_{2}\right](\mathrm{NCSe})_{2}$, are presented in Fig. 4 (a). The first part of the figure shows the evolution of the spectra between 280 and $100 \mathrm{~K}$. It can be observed that, when decreasing the temperature, a broad band present at $800-850 \mathrm{~nm}$ tends to disappear, whereas a new band, sharper, appears at $700 \mathrm{~nm}$. The absorptions in the $550-750 \mathrm{~nm}$ region can be assigned to both MLCT and $\mathrm{d}-\mathrm{d}$ transitions of the LS material, namely the ${ }^{1} \mathrm{~A}_{1} \rightarrow{ }^{1} \mathrm{~T}_{1}$. On the other hand, the broad peak at $800 \mathrm{~nm}$ is attributed to a $\mathrm{d}-\mathrm{d}$ band of the HS state of the compound, namely the ${ }^{5} \mathrm{~T}_{2} \rightarrow{ }^{5} \mathrm{E}$. At temperatures below $100 \mathrm{~K}$, a decrease of the band at $650 \mathrm{~nm}$ can be observed, associated with a re-increase of the band at $800 \mathrm{~nm}$. This is due to the fact that the same reflectivity experiment can also monitor any light-induced phenomena occurring at the surface of the sample. When the temperature is sufficiently low, relaxation of the photo-induced HS state is sufficiently slow and the light intensity at the surface of the sample is large enough to populate the photo-induced HS state. In order to have an easy comparison between the different metal dilutions, the reflectivity as a 
function of the temperature has been recorded at a given wavelength, namely $647 \mathrm{~nm}$, in the ${ }^{5} \mathrm{~T}_{2} \rightarrow{ }^{5} \mathrm{E}$ band of the HS state (Fig. 4 (b)). All the compounds exhibit the same general behaviour: starting from room temperature, the reflectivity decreases first between 250 and $200 \mathrm{~K}$, depending on the compound. Further cooling of the compound leads to a re-increase of this reflectivity. Again this behaviour corresponds (i) at high temperature to the thermal spin transition, and (ii) at low temperature to the population of a photo-induced high-spin state. The occurrence of the photo-induced phenomenon at low temperature implies that the lifetime of the photo-induced state can be studied using photomagnetic studies.
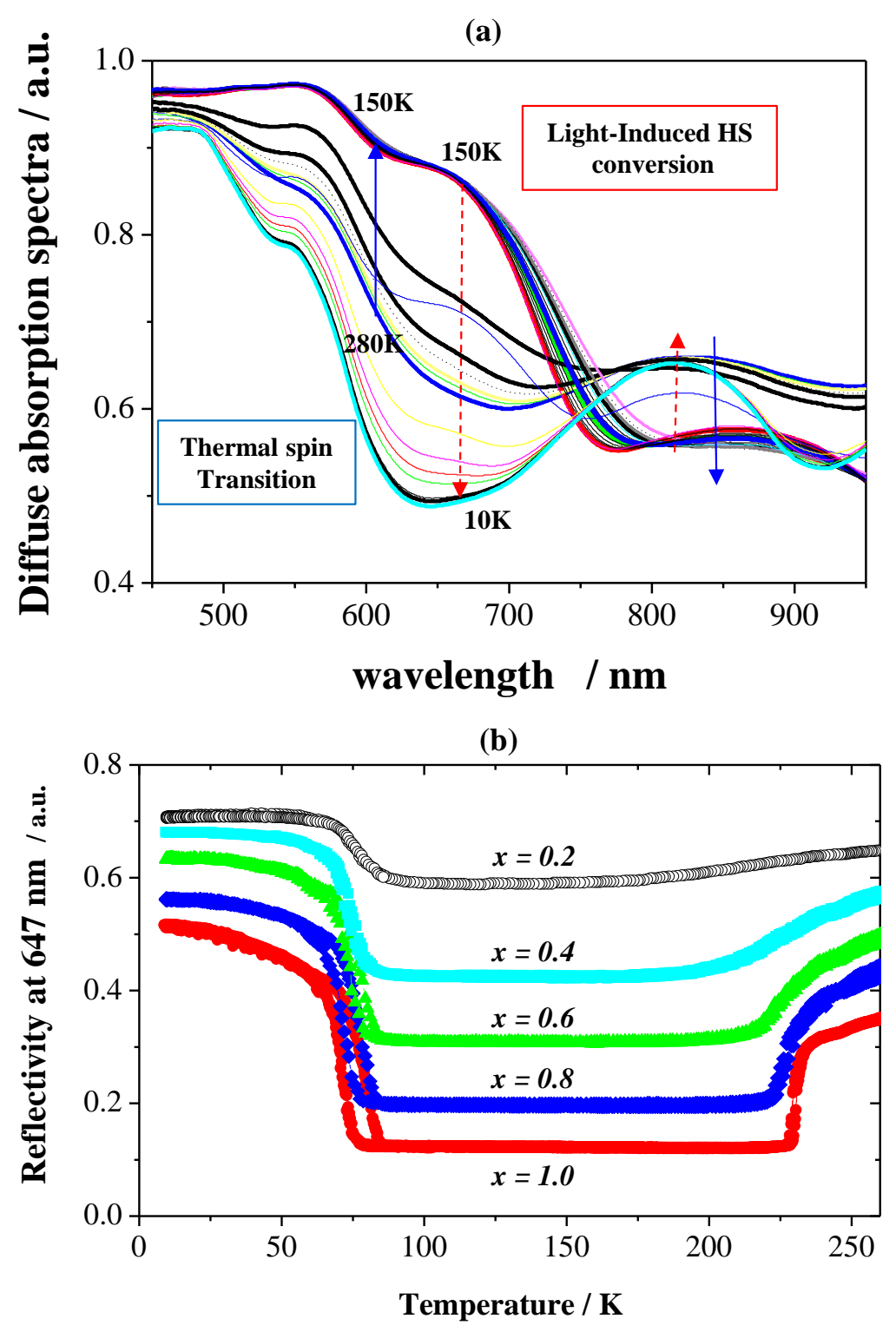

Fig 4. (a) Changes in the diffuse absorption spectra of the mixed $\left[\mathrm{Fe}_{0.4} \mathrm{Ni}_{0.6}(\mathrm{bpp})_{2}\right](\mathrm{NCSe})_{2}$ system upon cooling and upon light irradiation. (b) Evolution of the diffuse reflectivity signal recorded at $647 \mathrm{~nm}$ and generating LIESST below $80 \mathrm{~K}$ as function of $x$. 


\subsection{Photomagnetic properties}

The low $\rightarrow$ high spin photoconversion can also be investigated by photomagnetic studies. At $10 \mathrm{~K}$, the samples were irradiated with the most efficient wavelength to induce LIESST effect, that is, $647 \mathrm{~nm}$. This wavelength corresponds to a shoulder in the MLCT band of the diffuse absorption spectra (Fig. 4 (a)). Figure 5 reports the photomagnetic experiments performed on 1-5. After light excitation at $647 \mathrm{~nm}$ at $10 \mathrm{~K}$, the temperature was increased in the dark to record the T(LIESST) curve. The $\chi_{M} T$ product first increases upon warming from 10-30 K due to zero-field splitting of the high spin iron(II) ion [47]. Then after a plateau, the $\chi_{M} T$ value decreases sharply. The value of $\chi_{M} T$ at this plateau informs on the efficiency of the photoswitching: for all of them, a complete photoconversion is achieved. T(LIESST) is determined by the minimum of the derivative $\partial\left(\chi_{M} T\right) / \partial \mathrm{T}$ versus $\mathrm{T}$ (Insets, Fig. 5). The $\mathrm{T}$ (LIESST) values of all the metal-diluted complexes listed in Table 1 are almost identical at around $75 \mathrm{~K}$, with a slight decrease upon metal dilution.

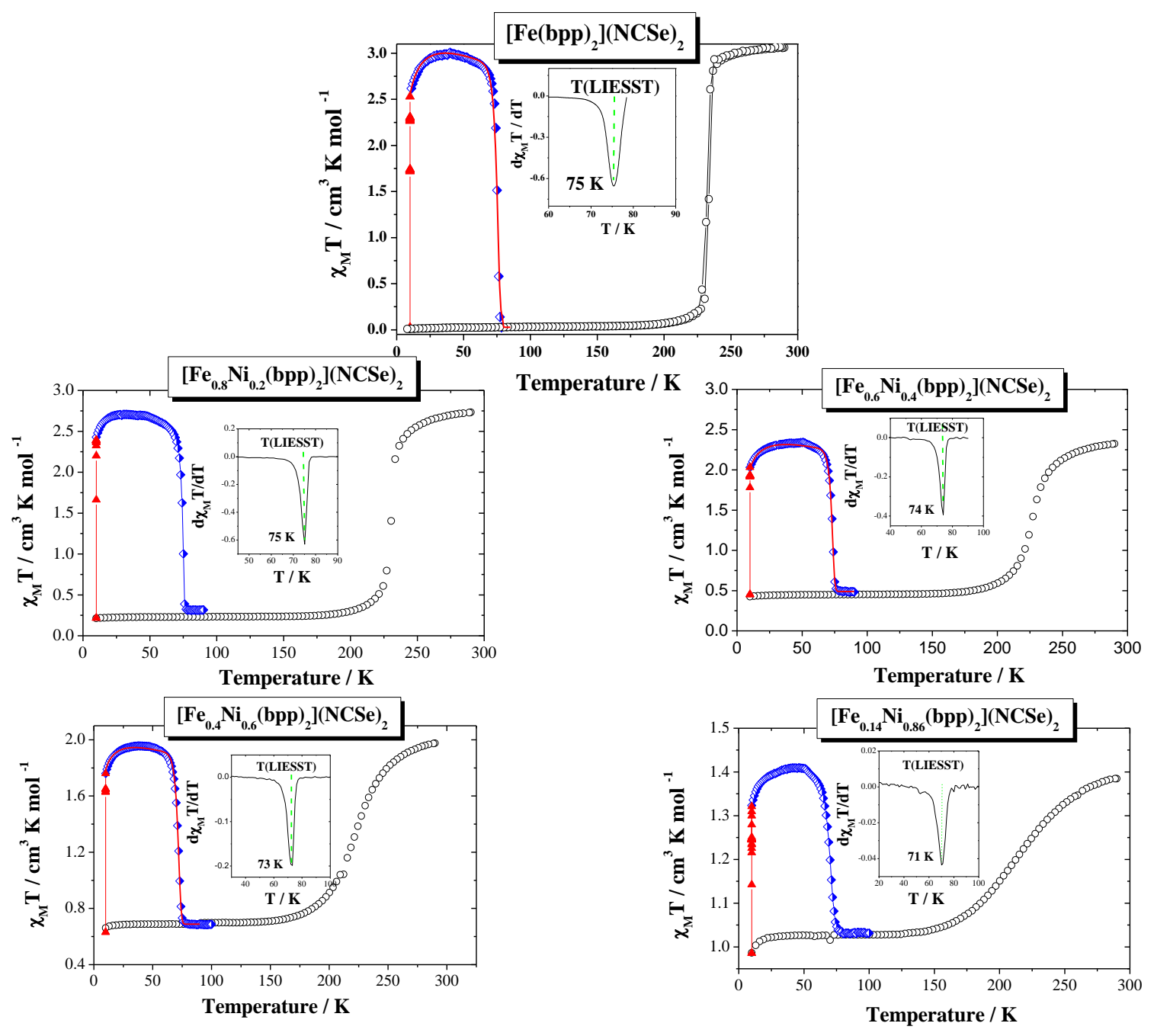

Fig 5. Temperature dependence of $\chi_{\mathrm{M}} T$ for $\left[\mathrm{Fe}_{\mathrm{x}} \mathrm{Ni}_{1-\mathrm{x}}(\mathrm{bpp})_{2}\right](\mathrm{NCSe})_{2}(\mathrm{O})=$ data recorded in cooling and warming modes without irradiation; $(\boldsymbol{\Delta})=$ data recorded with irradiation at $647 \mathrm{~nm}$ at $10 \mathrm{~K} ;(\diamond)=T($ LIESST) measurement, data recorded in warming mode with the laser turned off after irradiation for one hour. The solid line through the $T$ (LIESST) measurement shows the fit generated from the deduced experimental 
thermodynamic parameters $\left(E_{\mathrm{a}}, k_{\infty}\right.$ and $\left.E_{\mathrm{a}}{ }^{*}\right)$. The insets show the derivative $d \chi_{\mathrm{M}} T / d T v s$. $T$ curves, whose minimum corresponds to the $T($ LIESST) value.

Table 1. Magnetic and photomagnetic properties of the mixed $\left[\mathrm{Fe}_{\mathrm{x}} \mathrm{Ni}_{1-\mathrm{x}}(\mathrm{bpp})_{2}\right](\mathrm{NCSe})_{2}$ system. $T_{1 / 2}$ is the temperature at which the sample contains $50 \%$ of LS and HS molecules. T(LIESST) is the temperature at which the light-induced HS information was erased during warming from $10 \mathrm{~K}$ at a rate of $0.3 \mathrm{~K} \mathrm{~min}^{-1}$. For $x=1$ and $x$ $=0.6$, and 0.14 kinetic parameters as defined in eqn (5) and (6) are reported.

\begin{tabular}{cccccccc}
\hline SCO Systems & $\begin{array}{c}T_{1 / 2} \downarrow \\
(\mathrm{K})\end{array}$ & $\begin{array}{c}T_{1 / 2} \uparrow \\
(\mathrm{K})\end{array}$ & $\begin{array}{c}T(\text { LIESST }) \\
(\mathrm{K})\end{array}$ & $\begin{array}{c}k_{0} \\
\left(\mathrm{~s}^{-1}\right)\end{array}$ & $\begin{array}{c}k_{\infty} \\
\left(\mathrm{s}^{-1}\right)\end{array}$ & $\begin{array}{c}E_{\mathrm{a}} \\
\left(\mathrm{cm}^{-1}\right)\end{array}$ & $\begin{array}{c}E_{\mathrm{a}}{ }^{*} \\
\left(\mathrm{~cm}^{-1}\right)\end{array}$ \\
\hline$\left[\mathrm{Fe}(\mathrm{bpp})_{2}\right](\mathrm{NCSe})_{2}$ & 231 & 233 & 75 & $1.8 \times 10^{-5}$ & $7.2 \times 10^{6}$ & 1190 & 130 \\
{$\left[\mathrm{Fe}_{0.8} \mathrm{Ni}_{0.2}(\mathrm{bpp})_{2}\right](\mathrm{NCSe})_{2}$} & 229 & 229 & 75 & $/$ & $/$ & $/$ & $/$ \\
{$\left[\mathrm{Fe}_{0.6} \mathrm{Ni}_{0.4}(\mathrm{bpp})_{2}\right](\mathrm{NCSe})_{2}$} & 226 & 226 & 74 & $2.0 \times 10^{-5}$ & $1.5 \times 10^{7}$ & 1194 & 100 \\
{$\left[\mathrm{Fe}_{0.4} \mathrm{Ni}_{0.6}(\mathrm{bpp})_{2}\right](\mathrm{NCSe})_{2}$} & 221 & 221 & 73 & $2.5 \times 10^{-5}$ & $5.6 \times 10^{7}$ & 1210 & 55 \\
{$\left[\mathrm{Fe}_{0.14} \mathrm{Ni}_{0.86}(\mathrm{bpp})_{2}\right](\mathrm{NCSe})_{2}$} & 214 & 214 & 71 & $/$ & $/$ & $/$ & $/$ \\
\hline
\end{tabular}

\subsection{Relaxation kinetics}

To learn more about the lifetime of the photo-induced state, compounds 1,3 and 4 were systematically investigated from the relaxation kinetics point of view (Figure 6). For all the compounds, the HS fraction after photoexcitation remains constant with time at $10 \mathrm{~K}$, as a signature of the quantum tunneling region of the relaxation process. Between $60 \mathrm{~K}$ and $80 \mathrm{~K}$ the HS $\rightarrow$ LS relaxation is observed which corresponds to the thermally activated regime accessible with the SQUID apparatus. While compound $\mathbf{1}$ exhibits a self-accelerated relaxation process, this characteristic signature of cooperative materials disappears upon metal dilution to let place to stretched exponential relaxations. This behavior is coherent with the loss of cooperativity due to metal dilution. The relaxation curves were nicely simulated according to the mean field macroscopic equations of Hauser, which reflects the change in the energy barrier as a function of $\gamma_{\mathrm{HS}}$ (the fraction of spin centres in the sample that are high-spin at a given temperature) $[38,40,48]$ (see Equations 4, 5, 6 and 7) where $\alpha(T)=\left(E_{a} * / k_{\mathrm{B}} T\right)$ is the acceleration factor at a given temperature and the relaxation rate $k^{*}{ }_{H L}\left(T, \gamma_{\mathrm{HS}}\right)$ depends exponentially on both $\gamma_{\mathrm{HS}}$ and $T$ (eq. (4) and (5)).

$$
\frac{\partial \gamma_{H S}}{\partial t}=-k_{H L}^{*} \gamma_{H S}
$$

$k^{*}{ }_{\mathrm{HL}}\left(T, \gamma_{\mathrm{HS}}\right)=k_{\mathrm{HL}}(T) \cdot \exp \left[\alpha(T)\left(1-\gamma_{\mathrm{HS}}\right)\right]$

$k_{H L}(T)=k_{0}+k_{\infty} \cdot \exp \left(-E_{a} / \mathrm{k}_{\mathrm{B}} T\right)$

$$
\frac{\partial \gamma_{H S}}{\partial t}=-\gamma_{H S}\left\{k_{0}+k_{\infty} \cdot \exp \left(-E_{a} /_{k_{B} T}\right)\right\} \cdot \exp \left[\alpha(T)\left(1-\gamma_{H S}\right]\right.
$$


All the kinetic parameters such as the apparent activation energy $E_{a}$, the apparent preexponential factor, $k_{\infty}$, of the activated region as well as the rate constant, $k_{0}$, of quantum tunnelling region are calculated from the straight line fits given by the Arrhenius plot $\ln k_{H L}(T)$ $v s 1 / T$ (Fig. 6) and listed in Table 1. In this series, we also observed that $\mathrm{E}_{\mathrm{a}}$ remains almost constant while $k_{H L}(\mathrm{~T} \rightarrow \infty)$ (also written $k_{\infty}$ ) increases with increasing doping level. According to equation (6), an increase of $k_{\infty}$ will lead to a decrease of $T$ (LIESST), whereas an increase of $E_{\mathrm{a}}$ will lead to an increase of $T$ (LIESST). It seems that the metal dilution through the increase of $k_{\infty}$ parameters leads to a decrease of $T$ (LIESST) values. An elegant way to validate the parameters obtained from the simulation of the relaxation kinetics is to reproduce the experimental T(LIESST) curves. The procedure used for that takes carefully into account both time and temperature dependencies of the relaxation, and combines the quantum mechanical tunnelling and the thermally activated regions following eq. (7). In Fig. 5 we show the calculated $T$ (LIESST) curve deduced from the kinetics parameters listed in Table 1 for metal complexes $(x=1,0.6$ and 0.4$)$.
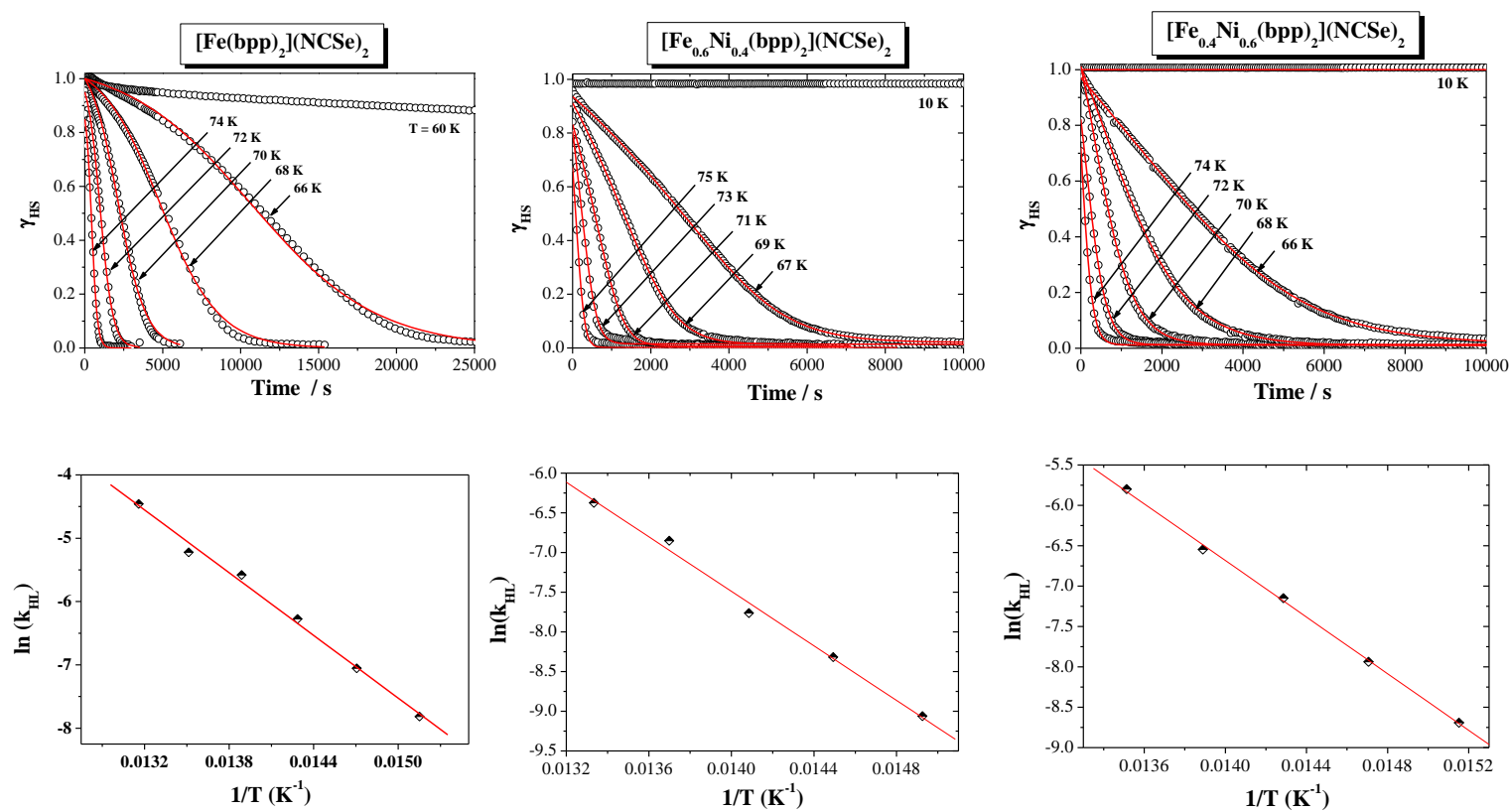

Fig 6. HS $\rightarrow$ LS relaxation at various temperatures for the mixed $\left[\mathrm{Fe}_{\mathrm{x}} \mathrm{Ni}_{1-\mathrm{x}}(\mathrm{bpp})_{2}\right](\mathrm{NCSe})_{2}$ systems $(\mathrm{x}=1,0,6$ and 0.4$)$. The solid lines are the fits obtained with the models described in the text. The corresponding Arrhenius plot of $\ln \left(\mathrm{k}_{\mathrm{HL}}\right)$ versus $1 / \mathrm{T}$ are given down. The lines represent the best linear simulations.

\subsection{Discussion}

Table 1, collects all the data obtained during this study. First of all, $\mathrm{T}_{1 / 2}$ decreases by $19 \mathrm{~K}$ between the pure compound $(x=1)$ and the most diluted compound $(x=0.14)$. In contrast, $\mathrm{T}\left(\right.$ LIESST) varies by only $4 \mathrm{~K}$, explained by an increase of $k_{H L}(\mathrm{~T} \rightarrow \infty)$ while the activation energy $E_{a}$ remains constant. These findings are very similar to those previously reported for the $\left[\mathrm{Fe}_{\mathrm{x}} \mathrm{Zn}_{1-\mathrm{x}}(\mathrm{bpp})_{2}\right](\mathrm{NCSe})_{2}$ series [30] and confirm that the $\mathrm{T}(\mathrm{LIESST})$ value is nearly independent of the metal dilution. However, it is important to note that the T(LIESST) value 
decreases substantially for $\left[\mathrm{Fe}_{\mathrm{x}} \mathrm{Ni}_{1-\mathrm{x}}\right]$ compounds. This is understandable according to the small ionic radius of nickel ion. We, also, previously reported the variation of T(LIESST) value in the $\left[\mathrm{Fe}_{\mathrm{x}} \mathrm{Mn}_{1-\mathrm{x}}(\mathrm{bpp})_{2}\right](\mathrm{NCSe})_{2}$ series. The results given by the studies of the $(2,6-$ bis(pyrazol-3-yl) pyridine) series diluted by three different ions, namely $\left[\mathrm{Fe}_{\mathrm{x}} \mathrm{M}_{1}\right.$ $\left.x(\mathrm{bpp})_{2}\right](\mathrm{NCSe})_{2}(\mathrm{M}=\mathrm{Mn}, \mathrm{Zn}$ and $\mathrm{Ni})$ are reported on Fig. 7. It clearly appears that, the dilution with manganese showed a slight increase of T(LIESST) with increasing doping level, this increase of T(LIESST) value being weaker or nonexistent in the case of dilution with zinc. Finally, the dilution with nickel, induced a decrease of the T(LIESST) with increasing metal dilution level. It is interesting to note that the variation of T(LIESST) value in the three cases, contradicts the rule stating that "the lower the thermal spin transition temperature $\left(\mathrm{T}_{1 / 2}\right)$, the higher the T(LIESST)". Basically it is expected that the T(LIESST) value increases with decreasing $T_{1 / 2}$, in agreement with the inverse-energy-gap law $[39,40]$ and with the empirical observed relation $\mathrm{T}($ LIESST $)=\mathrm{T}_{0}-0.3 \mathrm{~T}_{1 / 2}$ [42]. Concerning the thermal spin crossover, previous studies on this phenomenon have shown that any change of pressure in the lattice by chemical metal dilution or by external stimulus affects the Gibbs free energy through a change of the molecular volume of reaction giving rise to the additional term $\mathrm{p} \Delta \mathrm{V}_{\mathrm{HL}}[3,40]$. Thus, it appears that the host molecules in a doped system can affect the transition temperature, $T_{1 / 2}$, in two ways: (1) The role of the host molecules as defects in the lattice tends to lower $T_{1 / 2}$, as the transition becomes more gradual. (2) The ionic radius of the host complex may favor either one of the two spin states [21]. An explanation of the various observations in terms of the nucleation and growth mechanism of phase transitions in the solid state was given $[21,27(\mathrm{~b})]$. In the case of $\left[\mathrm{Fe}_{\mathrm{x}} \mathrm{Ni}_{1-\mathrm{x}}(\mathrm{bpp})_{2}\right](\mathrm{NCSe})_{2}$ series, the first situation seems to be predominant. Experiments are needed to directly control and monitor the number and nature of crystal defects and domains to clarify the situation.

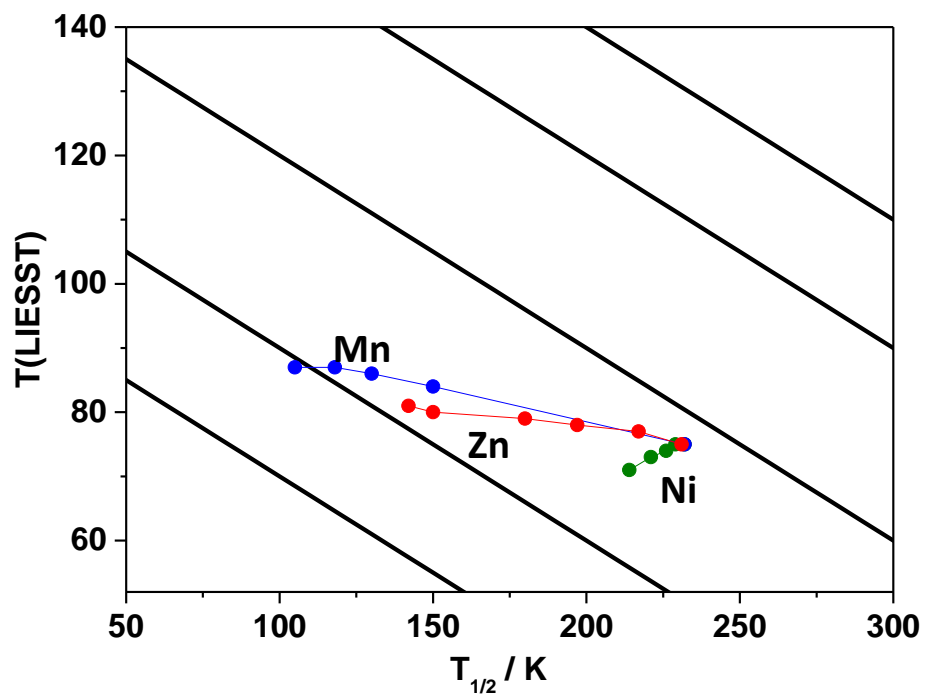

Fig 7. Evolution of the T(LIESST) vs $\mathrm{T}_{1 / 2}$ for $\left[\mathrm{Fe}_{\mathrm{x}} \mathrm{Ni}_{1-\mathrm{x}}(\mathrm{bpp})_{2}\right](\mathrm{NCSe})_{2},\left[\mathrm{Fe}_{\mathrm{x}} \mathrm{Zn}_{1-\mathrm{x}}(\mathrm{bpp})_{2}\right](\mathrm{NCSe})_{2}$ and $\left[\mathrm{Fe}_{x} \mathrm{Mn}_{1-}\right.$ $\left.x(\mathrm{bpp})_{2}\right](\mathrm{NCSe})_{2}$. 


\section{Conclusions}

We have reported the thermal and photo-induced spin-crossover properties of $\mathrm{Fe}_{\mathrm{x}} \mathrm{Ni}_{1-}$ $\left.x(\mathrm{bpp})_{2}\right](\mathrm{NCSe})_{2}$ systems and compare these results to previous ones obtained in the same series with $\mathrm{Zn}$ and $\mathrm{Mn}$ as doping metals. We have shown that dilution has a strong effect on magnetic and photomagnetic properties. The magnitude of these effects depends strongly on the nature of the diluting metal. All this may be understood as follows: manganese, having an ionic radius larger than that of the iron in its HS state, stabilizes the HS state by exerting a "negative" internal pressure, which leads to an important decrease of $\mathrm{T}_{1 / 2}$ and a slight increase in the value of T(LIESST). Zinc, with a similar ionic radius than iron HS, causes no change in $\mathrm{T}$ (LIESST) but shift $\mathrm{T}_{1 / 2}$ towards lower temperatures. Finally, nickel with an almost intermediate ionic radius between iron $\mathrm{HS}$ and iron $\mathrm{LS}\left\{r\left(F e_{H S}^{2+}\right)-r\left(N i_{H S}^{2+}\right)=\right.$ $9 \mathrm{pm} ; r\left(N i_{H S}^{2+}\right)-r\left(F e_{L S}^{2+}\right)=8 \mathrm{pm}$, will tend to stabilize slightly the state of smaller volume, namely the LS state. This therefore generates a slight decrease in T(LIESST) and $\mathrm{T}_{1 / 2}$ with increasing doping level.

\section{Acknowledgements}

We thank the University of Ziguinchor and its Department of Cooperation and Research, the Ministry of Higher Education and Research of Sénégal (Program FIRST). This work was also supported by the University of Bordeaux, the CNRS, the Aquitaine Region and by the LabEx AMADEus (ANR-10LABX-42) within IdEx Bordeaux (ANR-10-IDEX-03-02), i.e. the Investissements d'Avenir programme of the French government managed by the Agence Nationale de la Recherche.

\section{References}

[1] a) H. A. Goodwin, Top. Curr. Chem. 233 (2004) 59-90; b) G. J. Long, F. Grandjean and D. L. Reger, Top. Curr. Chem. 233 (2004) 91; c) H. Toftlund and J.-J. McGarvey, Top. Curr. Chem. 233 (2004) 151; d) P. Gutlich, Y. Garcia and H. A. Goodwin, Chem. Soc. Rev. 29 (2000) 419.

[2] Spin Crossover in Transition Metal Compounds, edited by P.Gutlich and H. A. Goodwin, Top. Curr. Chem.; Springer: New York, 2004.

[3] P. Gutlich, A. Hauser, and H. Spiering, Angew. Chem. 33 (1994) 2024.

[4] P. Guionneau, M. Marchivie, G. Bravic, J.-F. Létard and D. Chasseau, Top. Curr. Chem., 2004, $234,97$.

[5] P. Guionneau, Dalton Trans. 43 (2014) 382.

[6] P. Gütlich, H.A. Goodwin, in: P. Gütlich, H.A. Goodwin (Eds.), Spin Crossover in Transition Metal Compounds I, no. 233 in Top. Curr. Chem., Springer, Berlin Heidelberg, 2004, pp. 1.

[7] P. Gütlich, A. B. Gaspar and Y. Garcia, Beilstein J. Org. Chem. 9 (2013) 342.

[8] C. Lefter, R. Tan, S. Tricard, J. Dugay, G. Molnár, L. Salmon, J. Carrey, A. Rotaru, A. Bousseksou, Polyhedron 102 (2015) 434.

[9] P. Gütlich, H. A. Goodwin, Top. Curr. Chem. 233 (2004) 1.

[10] A. C. Aragonès, D. Aravena, J.I. Cerdà, Z. Acis-Castillo, H. Li, J. A. Real, F. Sanz, J. Hihath, E. Ruiz, I. Diez-Perez, Nano Lett. 16 (2016) 218.

[11] O. Kahn, C. J. Martinez, Science. 279 (1998) 44.

[12] T. Miyamachi, M. Gruber, V. Davesne, M. Bowen, S. Boukari, L. Joly, F. Scheurer, G. Rogez, T. Kazu Yamada, P. Ohresser, E. Beaurepaire, W. Wulfhekel, Nat. Comm. 3 (2012) 938/1.

[13] G. Molnar, L. Salmon, W. Nicolazzi, F. Terki, A. Bousseksou, J. Mater. Chem. C 2 (2014) 1360.

[14] J.-F. Létard, P. Guionneau, L. Goux-Capes, Top. Curr. Chem. 235 (2004) 221.

[15] R. Bertoni, M. Cammarata, M. Lorenc, S. Matar, J-F. Létard, H-T. Lemke, and Eric Collet, Acc. Chem. Res. 48 (2015) 774-781.

[16] J.-J. McGarvey, I. Lawthers, J. Chem. Soc., Chem. Comm. 16 (1982) 906.

[17] S. Decurtins, P. Gütlich, C. P Köhler, H. Spiering, A. Hauser, Chem. Phys. Lett. 105 (1984) 1.

[18] A. Hauser, Chem. Phys. Lett. 124 (1986) 543.

[19] P. Ganguli, P. Gütlich, E. W. Müller, Inorg. Chem. 21 (1982) 3429. 
[20] M.S. Haddad, W. D. Federer, M. W. Lynch, D. N. Hendrickson, J. Am. Chem. Soc. 102 (1980) 1468.

[21] M.S. Haddad, W.D. Federer, M.W. Lynch, D.N. Hendrickson, Inorg. Chem. 20 (1981) 131.

[22] V. Varma, J.R. Fernàndes, Chem. Phys. Lett. 167 (1990) 367.

[23] J.-P. Martin, J. Zarembowitch, A. Dworkin, J.G. Haasnoot, F. Varret, Inorg. Chem. 33 (1994) 2617.

[24] J.-P. Martin, J. Zarembowitch, A. Bousseksou, A. Dworkin, J. G. Haasnoot, F. Varret, Inorg. Chem. 33 (1994) 6325

[25] T. Tayagaki, A. Galet, G. Molnar, M. Carmen Munoz, A. Zwick, K. Tanaka, J.-A. Real and A. Bousseksou, J. Phys. Chem. B. 109 (2005) 14859.

[26] C. Baldé, C. Desplanches, P. Gütlich, E. Freysz, J.-F. Létard, Inorg. Chim. Acta. 361 (2008) 3529-3533.

[27] a) C. Baldé, C. Desplanches, O. Nguyen, J.-F. Létard, J. Phys. Conf. Ser. 148 (2009) 012026/1-012026/9 ; (b) G. Lebedev, S. Pillet, C. Baldé, P. Guionneau, C. Desplanches and J.-F. Létard, IOP Conf. Ser.: Mater. Sci. Eng. 5 (2009) 012025.

[28] C. Baldé, C. Desplanches, A. Wattiaux, P. Guionneau, P. Gütlich, J.-F. Létard, Dalton Trans. (2008) 2702.

[29] C. Baldé, C. Desplanches, M. Grunert, Y. Wei, P. Gütlich, J.-F. Létard, Eur. J. Inorg. Chem. (2008) 5382.

[30] C. Baldé, C. Desplanches, F. Le Gac, P. Guionneau, and J.-F. Létard, Dalton Trans. 43 (2014) 7820.

[31] N. Paradis, G. Chastanet, J.-F. Létard, Eur. J. Inorg. Chem. (2012) 3618.

[32] N. Paradis, G. Chastanet, F. Varret and J.-F. Létard, Eur. J. Inorg. Chem. (2013) 968.

[33] N. Paradis, G. Chastanet, T. Palamarciuc, P. Rosa, F. Varret, K. Boukheddaden and J.-F. Létard, J. Phys. Chem. C 119 (2015) 20039.

[34] P. Chakraborty, C. Enachescu, C. Walder, R. Bronisz and A. Hauser, Inorg. Chem. 51 (2012) 9714.

[35] I. Krivokapic, P. Chakraborty, C. Enachescu, R. Bronisz and A. Hauser, Inorg. Chem. 50 (2011) 1856.

[36] S. Zheng, M-A. Siegler, J-S. Costa, W-T. Fu and S. Bonnet, Eur. J. Inorg. Chem. (2013) 1033.

[37] R. Ohtani, S. Egawa, M. Nakaya, H. Ohmagari, M. Nakamura, L-F. Lindoy and S. Hayami, Inorg. Chem. 55 (2016) 3332-3337.

[38] A. Hauser, Top. Curr. Chem. 234 (2004) 155.

[39] A. Hauser, C. Enachescu, M.L. Daku, A. Vargas, N. Amstutz, Coord. Chem. Rev. 250 (2006) 1642.

[40] A. Hauser, Coord. Chem. Rev. 111 (1991) 275.

[41] A. Hauser, J. Jeftic, H. Romstedt, R. Hinek, H. Spiering, Coord. Chem. Rev. 190-191 (1999) 471.

[42] a) J.-F. Létard, L. Capes, G. Chastanet, N. Moliner, S. Létard, J. A. Real, O. Kahn, Chem. Phys. Lett. 333 (1999) 115; b) S. Marcen, L. Lecren, L. Capes, H. A. Goodwin, J.-F. Létard, Chem. Phys. Lett. 358 (2002) 87-95; c) J.-F. Létard, P. Guionneau, O. Nguyen, J. S. Costa, S.Marcén, G. Chastanet, M. Marchivie, L. Capes, Chem. Eur. J. 11 (2005) 4582; d) J.-F. Létard, J. Mater. Chem. 16 (2006) 2550; e) J.-F. Létard, G. Chastanet, P. Guionneau, C. Desplanches, in Spin Crossover Materials: Properties and Applications, Ed. Malcom A. Halcrow, (2013), John Wiley \& sons, 475.

[43] J.F. Létard, G. Chastanet, O. Nguyen, S. Marcen, M. Marchivie, P. Guionneau, D. Chasseau, P. Gütlich, Monatsh. Chem. 134 (2003) 165.

[44] R. D. Shannon, Acta Crystallogr, Sect. A. 32 (1976) 751.

[45] K. H. Surgiyarto, M. L. Sculddler, D.C. Craig, H. A. Goodwin, Aust. J. Chem. 53 (2000) 755.

[46] J.-F. Létard, P. Guionneau, L. Rabardel, J. A. K. Howard, A. E. Goeta, D. Chasseau, O. Kahn, Inorg. Chem. 37 (1998) 4432.

[47] O. Kahn, Molecular Magnetism, VCH, Weinheim, Germany, 1993.

[48] A. Hauser, P. Gütlich and H. Spiering, Inorg. Chem. 25 (1986) 4245. 
Table of Contents.

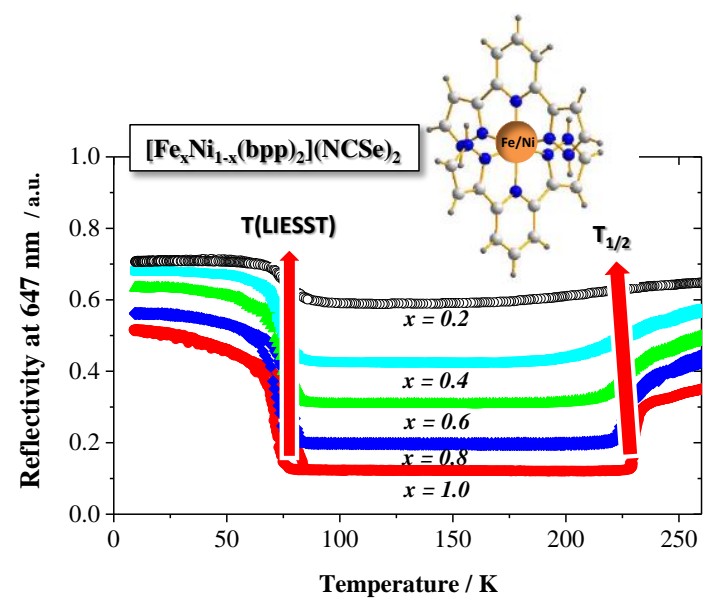

Effects of Metal Dilution on the Spin-Crossover Behavior and Light Induced Bistability of Iron(II) in $\left[\mathrm{Fe}_{x} \mathrm{Ni}_{1-x}(\mathrm{bpp})_{2}\right](\mathrm{NCSe})_{2}$

Chérif Baldé*, Cédric Desplanches, Jean François Létard, and Guillaume Chastanet*

The thermal and light-induced spin-crossover behaviors of $\left[\mathrm{Fe}_{\mathrm{x}} \mathrm{Ni}_{1-\mathrm{x}}(\mathrm{bpp})_{2}\right](\mathrm{NCSe})_{2}$ solid solutions (bpp = 2,6-bis(pyrazol-3-yl)pyridine), were studied and compared to $\mathrm{Zn}$ (II) and $\mathrm{Mn}$ (II) solid solutions, giving a first global view of dilution effects on the spin-crossover properties. 